\title{
Opioids for chronic refractory breathlessness: patient predictors of beneficial response
}

\author{
Miriam J. Johnson ${ }^{1}$, J. Martin Bland², Stephen G. Oxberry ${ }^{3}$, Amy P. Abernethy ${ }^{4}$ \\ and David C. Currow
}

Affiliations:

'Hull York Medical School, University of Hull, Hull,

${ }^{2}$ Dept of Health Sciences, University of York, York, and

${ }^{3}$ Kirkwood Hospice, Huddersfield, UK.

${ }^{4}$ Division of Medical Oncology, Dept of Medicine, Duke University Medical Centre, Durham, NC, USA.

${ }^{5}$ Palliative and Supportive Services, Flinders University, Adelaide, Australia.

\section{Correspondence:}

M.J. Johnson, Hull York Medical School, Hertford Building, The University of Hull, Cottingham Road, Hull, HU6 7RX, UK.

E-mail: miriam.johnsonahyms.ac.uk

ABSTRACT Chronic refractory breathlessness is common and distressing in advanced disease. Despite level I evidence to support the use of opioids for this symptom, not all patients benefit. This study aimed to discover which patient characteristics predict those most likely to gain improvement in breathlessness.

This is an international, multicentre, retrospective analysis of 213 individual pooled datasets from four clinical trials of an opioid for chronic refractory breathlessness. "Response to opioid" was defined as 1) an absolute value of $\geqslant 10 \mathrm{~mm}$ improvement on the visual analogue scale (VAS) and 2) a relative value of $\geqslant 10 \%$ improvement from baseline VAS. We investigated baseline predictors using logistic regression.

In the final model, higher baseline breathlessness intensity scores strongly predicted absolute and relative response $(\mathrm{p}<0.001)$. Younger age also predicted relative response $(\mathrm{p}=0.025)$; functional status and dominant cause of breathlessness did not. Some evidence supported the descriptor "not enough air", but was not statistically significant $(\mathrm{p}=0.052)$.

A therapeutic trial of opioids is appropriate, irrespective of the cause of the breathlessness or functional status. Younger people or those with worse breathlessness are more likely to benefit. Opioids have a role in the management of chronic refractory breathlessness, but net benefit for individuals must be optimised.

@ERSpublications

A role for opioids in the management of chronic refractory breathlessness; net benefit for individuals must be optimised http://ow.ly/kRf22

Earn CME accreditation by answering questions about this article. You will find these at the back of the printed copy of this issue or online at www.erj.ersjournals.com/site/misc/cmeinfo.xhtml

Received: Sept 042012 | Accepted after revision: Dec 102012 | First published online: Dec 202012

Conflict of interest: Disclosures can be found alongside the online version of this article at www.erj.ersjournals.com

Copyright @ERS 2013 


\section{Introduction}

Chronic refractory breathlessness remains a distressing and limiting symptom, common in many advanced diseases [1-3]. It affects all aspects of life for the patient and those who care for them. Improvement in chronic refractory breathlessness, by definition, is difficult. The concept of "total breathlessness" captures its multifactorial nature; breathlessness generated and exacerbated by varying interplays between physical, psychosocial and spiritual factors [4, 5].

This understanding is reflected in the complex interventions developed and evaluated for breathlessness management using a toolkit of nonpharmacological and pharmacological approaches [6-8]. The aims of management are broad, and include not only reduction in intensity of breathlessness, but also reduction in distress due to breathlessness, an increase in mastery over, and of coping with, breathlessness and, ideally, an increase in exercise tolerance and meaningful activity. Even small improvements in breathlessness intensity (improvement by one point on a 0-10 numerical rating scale (NRS) or $10 \mathrm{~mm}$ on a $0-100-\mathrm{mm}$ visual analogue (VAS) scale anchored with $0=$ "no breathlessness" and 10 or $100=$ "worst imaginable breathlessness") may be clinically relevant to people with chronic refractory breathlessness [9-12]. Thus, careful assessment of individual response to therapeutic strategies may make an important difference to quality of life.

Some questions remain unanswered, but a growing evidence base supports the use of opioids for the alleviation of chronic refractory breathlessness [13]. Most studies confirm efficacy for reduction of intensity, although data from people with breathlessness due to chronic heart failure are less consistent [14-17]. There are some data to support opioid-related improvement in exercise tolerance, although whether this translates to meaningful increase in activity is unknown [13], and neuroimaging and exercise laboratory studies are contributing to an understanding of mechanisms of action [18-21].

\section{What is known about predictors of response to opioids?}

Hypothesis-generating secondary analyses from three studies contribute to our current knowledge [16, 22, 23]. First, data from a placebo crossover randomised controlled trial (RCT) of morphine in 48 participants with chronic refractory breathlessness due to a range of aetiologies provided some evidence that baseline characteristics (age, sex, functional status, disease aetiology, use of oxygen or breathlessness intensity) may help to predict response. Participants who were younger $(<75$ years $)$ and had better functional status (European Oncology Co-operative Group (ECOG) status $<2$ ) were more likely to respond [23]. People with cardiovascular disease as the predominant cause were also more likely to respond $(p=0.05)$, but this group was very small $(n=4)$. Interestingly, there did not appear to be any relationship between more intense baseline breathlessness and response to morphine, which is unexpected given the greater scope for improvement with worse baseline scores. Second, data from a placebo-controlled randomised crossover trial of morphine or oxycodone in 39 participants with breathlessness due to chronic heart failure failed to demonstrate any effect of sex, aetiology of heart failure, concurrent cardiac medication or baseline severity of heart failure (assessed by $\mathrm{N}$-terminal pro-brain natriuretic peptide, ejection fraction or tolerated percentage of recommended angiotensin inhibition) on response to opioids [16]. Third, a randomised continuous sequential clinical trial assessing the response in breathlessness from breakthrough doses of morphine in 35 participants with terminal cancer found that those with lower baseline breathlessness intensity had a three times greater response to morphine than those with more severe breathlessness, although this was not statistically significant $(\mathrm{p}=0.1)$ [22]. No study was adequately powered to answer these subgroup questions, so formal conclusions cannot be drawn.

Which patient characteristics predict those most likely to gain improvement in breathlessness? In order to investigate potential predictors of breathlessness response to opioids in a larger sample of participants, we pooled the individual data from three placebo-controlled, randomised trials of morphine or oxycodone and one prospective cohort dose increment and pharmacovigilance study of morphine [14, 16, 17, 24]. All participants had chronic refractory breathlessness due to advanced disease, and the primary outcome measure was breathlessness intensity in all studies.

\section{Participants and methods \\ Design}

This was an international, multicentre, retrospective analysis of individual pooled data from 178 clinical trial participants with chronic refractory breathlessness treated with morphine or oxycodone for the management of breathlessness. Of these, 35 provided data from separate periods of exposure to two different opioids to give a total of 213 sets of data. Anonymised individual participant data were obtained from the chief investigators and an analysis of the pooled individual data was performed. Confirmation that National Health Service ethical permission was not required for pooling of anonymised data for secondary 
TABLE 1 Contributing studies to a pooled analysis of predictors of response to opioids for chronic refractory dyspnoea due to a range of underlying aetiologies

\begin{tabular}{|c|c|c|c|c|c|c|}
\hline $\begin{array}{l}\text { First author } \\
\text { [ref.] }\end{array}$ & Design & $\begin{array}{c}\text { Subjects } \\
\mathrm{n}\end{array}$ & Aetiology & $\begin{array}{l}\text { Functional } \\
\text { measure used }\end{array}$ & $\begin{array}{c}\text { Primary outcome } \\
\text { measure }\end{array}$ & Primary study findings \\
\hline ABERNETHY [14] & $\begin{array}{l}\text { Placebo-controlled randomised } \\
\text { crossover trial ( } 80 \% \text { power) } \\
\text { Intervention: } 4 \text { days oral } \\
\text { morphine (sustained release) }\end{array}$ & 48 & $\begin{array}{l}\text { COPD }(88 \%) \\
\text { Cancer }(6 \%) \\
\text { Other }(6 \%)\end{array}$ & ECOG status & VAS intensity & $\begin{array}{l}\text { Better scores in the morphine } \\
\text { arm } \\
\text { Morning: } 6.6 \mathrm{~mm}(95 \% \mathrm{Cl} \\
\text { 1.6-11.6 mm; } \mathrm{p}=0.011) ; \\
\text { evening: } 9.5 \mathrm{~mm}(3.0-16.1 \mathrm{~mm} ; \\
\quad p=0.006)\end{array}$ \\
\hline JoHNSON [17] & $\begin{array}{l}\text { Pilot placebo-controlled } \\
\text { randomised crossover trial } \\
\text { Intervention: } 4 \text { days oral } \\
\text { morphine }\end{array}$ & 10 & $\mathrm{CHF}$ & NYHA class & VAS intensity & $\begin{array}{c}\text { Morphine arm: } 23-\mathrm{mm} \text { reduction } \\
\text { by day } 2 \text { ( } \mathrm{p}=0.02 \text { ), sustained for } \\
\text { duration of dosing } \\
\text { Placebo arm: } 13-\mathrm{mm} \text { reduction } \\
\text { by day } 2 \text { (NS), reverted to } \\
\text { baseline by day } 4\end{array}$ \\
\hline OXBERRY [16] & $\begin{array}{l}\text { Placebo-controlled randomised } \\
\text { crossover trial ( } 80 \% \text { power) } \\
\text { Intervention: } 4 \text { days oral } \\
\text { morphine or } 4 \text { days oxycodone }\end{array}$ & 37 & $\mathrm{CHF}$ & $\begin{array}{l}\text { NYHA class } \\
\text { and KPS }\end{array}$ & NRS intensity & $\begin{array}{l}\text { NS difference between opioid and } \\
\text { placebo or between the two } \\
\text { types of opioid: }-1.37 \text { for placebo } \\
\text { group versus }-0.41 \text { for morphine } \\
\text { group ( } p=0.13 \text { ) and }-1.29 \text { for } \\
\text { oxycodone group }(p=0.90 \text { ) }\end{array}$ \\
\hline
\end{tabular}

COPD: chronic obstructive pulmonary disease; ECOG: European Co-operative Oncology Group; VAS: visual analogue scale; RLD: restrictive lung disease; NNT: number needed to treat for one person to benefit; NNH: number needed to harm; CHF: chronic heart failure; NYHA: New York Heart Association; NS: not significant; KPS: Karnofsky Performance Status; NRS: numerical rating scale.

analysis was obtained. Appropriate ethics approval had been obtained for each of the contributing studies and all participants gave informed written consent.

\section{Methods}

Key features of the contributing four studies are seen in table 1; the methods are described in detail elsewhere [14, 16, 17, 24]. In summary, three were placebo-controlled, randomised crossover trials, two of which had sufficient complete datasets to allow an $80 \%$ power of detecting a change of $10 / 100 \mathrm{~mm}$ on a VAS or one point on a NRS. The third was a pilot study [17]. These crossover studies compared 4 days of morphine with 4 days of placebo, with the addition by OXBERRY et al. [16] of a third arm with 4 days of oxycodone. There was one phase II cohort study examining breathlessness response to morphine dose increments [24]. The studies by ABERNETHY et al. [14] and OXBERRY et al. [16] provided data for two of the three preliminary studies of baseline predictors of response described above.

\section{Study participants}

All participants had chronic refractory breathlessness. A variety of primary causes of the breathlessness were represented. Two studies included only those with chronic heart failure (CHF) [16, 17]; the other two studies included participants predominantly with chronic obstructive pulmonary disease (COPD) [14, 24]. Because there was only one participant with motor neurone disease, this case was dropped by the statistical algorithm and is not represented in the results.

\section{Data elements}

Baseline characteristics common to all four studies were; age, sex, disease aetiology, breathlessness intensity and a measure of functional status.

\section{Measurement of breathlessness}

As three studies used the VAS, and both NRS and VAS appear to be reported by patients in a linear fashion [25], NRS intensity scores were represented as equivalent to $0-100 \mathrm{~mm}$ in the combined dataset. An empirical conversion table to approximate equivalent performance status scores between ECOG and the 
Karnofsky Performance Scale (KPS) has been published [26]. This conversion was used and performance scores for participants in the study using ECOG were entered as the equivalent KPS score. There are no published data regarding the equivalence of New York Heart Association (NYHA) class and KPS. However, both baseline KPS and NYHA status were recorded in the OXBERRY et al. [16] study, and unpublished data including KPS and NYHA status from 101 recruits to a study currently recruiting people with heart failure (Oxygen-HF trial; registered at www.anzctr.org.au with identifier number ACTRN12609000103268; personal communication) gave a combined dataset of 176 KPS/NYHA pairs. An association between the two measures was confirmed, then linear regression was used to predict KPS from NYHA and the predicted score rounded to an integer and then to $10 \mathrm{~s}$, and then the KPS for patients in the study by JOHNSON et al. [17] was estimated from the NYHA class. A more detailed description is given elsewhere [27].

\section{Definition of response}

"Response to opioid" was defined in two ways. First, as an absolute value of $\geqslant 10 \mathrm{~mm}$ improvement on the VAS and, second, as a relative value of $\geqslant 10 \%$ improvement from each participant's own baseline VAS value, which was an arbitrary measure used in the study by CurRow et al. [24].

\section{Statistical analysis}

The analysis looked first at absolute responders, and second at relative responders.

We used logistic regression to investigate baseline predictors. We used stepwise analysis with backwards elimination; at each stage we removed the variable with the largest nonsignificant p-value and then repeated this until there were no nonsignificant predictors. In the regression analyses, we included "study" as a variable to account for differences between countries and study designs. Participants from the OXBERRY et al. [16] study are included twice (morphine and oxycodone arms) and to allow for this we used robust standard errors, with each person in this study being defined as a cluster.

Study of origin was included as a variable in all analyses. As there were four studies, in order to model the effect of each study we generated three variables to allow "study" to be included. The reference study was that of ABERNETHY et al. [14] as this was the largest RCT. For the other three studies, we added study variables equal to one, indicating that this was the study of origin for this participant, and zero otherwise. For example, the variable "Currow" was equal to 1.0 for patients from the Currow et al. [24] study and zero otherwise, the variable "Johnson" was equal to 1.0 for patients from the JoHnson et al. [17] study and zero otherwise, etc. For participants from the study by ABERNETHY et al. [14], all three study variables were zero. In the same way, for the five disease categories, four variables were generated, with the reference category being heart failure.

Two studies (ABERNETHY et al. [14] and OXBERRY et al. [16]) had also documented participant breathlessness descriptors $(\mathrm{n}=107)$. Only the descriptors 3, 4, 5, 10 and 11 (table 2), were used in the analysis because these were the five most frequently given. For both absolute and relative responses, we tried adding each of the descriptors singly to the final baseline variables regression model rather than including all possible descriptors in the original stepwise regression analysis.

\section{Sensitivity analysis}

As it might be predicted that those with higher breathlessness baseline intensity scores would have a greater chance of having a demonstrable improvement, a sensitivity analysis was performed, removing all those with baseline breathlessness scores of $<30 \mathrm{~mm}$.

TABLE 2 Baseline descriptors derived from the work of SIMON et al. [28] used in the analysis

Number Description

\begin{tabular}{lc}
\hline 3 & "Does not go in" \\
4 & "Shallow breathing" \\
5 & "More effort" \\
10 & "Out of breath" \\
11 & "Cannot get enough air" \\
\hline
\end{tabular}

Descriptors were presented in random order for each participant. 


\section{Results}

Baseline characteristics of the combined dataset are presented in table 3; these were the available potential predictors of therapeutic response investigated: age, sex, underlying aetiology, baseline breathlessness intensity and functional ability.

\section{Absolute response}

Absolute therapeutic response was defined as an absolute difference in breathlessness intensity observed for individuals exposed to opioid or placebo. Logistic regression demonstrated that younger age $(\mathrm{p}=0.039)$ and higher baseline breathlessness intensity $(\mathrm{p}<0.001)$ were likely predictors of absolute response (table 4 ).

The final model after stepwise regression is that higher baseline breathlessness intensity $(\mathrm{p}<0.001)$ continued to be a very significant predictor of response (table 5).

\section{Relative response}

Relative therapeutic response was defined as a difference in breathlessness intensity referenced to the proportion of breathlessness at baseline, observed for individuals exposed to opioid or placebo. The final model after stepwise regression for relative therapeutic response mimicked absolute response (table 5) in terms of predictors identified, although the findings were more significant with smaller p-values; younger age remained a predictor (younger age $\mathrm{p}=0.025$; higher baseline breathlessness intensity $\mathrm{p}<0.001$ ).

\section{Descriptors}

Descriptors of breathlessness were explored in both the absolute and relative response models. We added each of the five most commonly cited descriptors (descriptors 3, 4, 5, 10 and 11) singly to the final baseline variables model. For absolute response, there was weak evidence for the descriptor "cannot get enough air" (D11) as a predictor when adjusted for age and baseline intensity $(\mathrm{p}=0.052)$. For relative response, again there was only weak evidence for descriptor "cannot get enough air" ( $p=0.061)$. There was no evidence for any other descriptor predicting response.

\section{Sensitivity analyses}

The repeat analysis removing participant data where the baseline breathlessness score was $<30 \mathrm{~mm}$ included 128 datasets. The predictive significance of higher baseline breathlessness remained for an absolute response $(\mathrm{p}=0.009)$ but was lost for a relative response $(\mathrm{p}=0.055)$.

\section{Discussion}

This larger dataset confirms younger age to be a predictor of breathlessness response to an opioid while controlling for the other key available data including functional status. Unlike previously published

TABLE 3 Baseline demographic and clinical data for four studies that prospectively evaluated the use of opioids for chronic refractory dyspnoea

\begin{tabular}{|c|c|c|c|c|c|c|}
\hline \multirow[t]{2}{*}{ Variable } & \multirow[t]{2}{*}{ AвERNEthy [14] } & \multirow[t]{2}{*}{ CuRrow [24] } & \multirow[t]{2}{*}{ JoHNSON [17] } & \multicolumn{2}{|c|}{ OXBERRY [16] } & \multirow[t]{2}{*}{ Combined } \\
\hline & & & & Morphine & Oxycodone & \\
\hline Age & $73.1 \pm 9.5(41-89)$ & $\begin{array}{c}74.8 \pm 8.9 \\
(51-88)\end{array}$ & $\begin{array}{c}66.2 \pm 11.6 \\
(45-83)\end{array}$ & $\begin{array}{l}70.2 \pm 11.1 \\
(41-89)\end{array}$ & $\begin{array}{l}70.2 \pm 11.1 \\
(41-89)\end{array}$ & $\begin{array}{l}73.1 \pm 9.5 \\
(41-89)\end{array}$ \\
\hline \multicolumn{7}{|l|}{ Sex } \\
\hline \multicolumn{7}{|l|}{ Disease } \\
\hline Heart failure & $0(0)$ & $3(3.5)$ & 10 (100) & $35(10)$ & $35(10)$ & 83 (39) \\
\hline COPD & 42 (89) & $42(49)$ & $0(0)$ & $0(0)$ & $0(0)$ & 84 (39) \\
\hline MND & $1(2)$ & $0(0)$ & $0(0)$ & $0(0)$ & $0(0)$ & $1(<1)$ \\
\hline Cancer & $3(6)$ & $24(28)$ & $0(0)$ & $0(0)$ & $0(0)$ & $27(13)$ \\
\hline RLD & $2(4)$ & 16 (19) & $0(0)$ & $0(0)$ & $0(0)$ & $18(8)$ \\
\hline
\end{tabular}

Data are presented as $\mathrm{n}$, mean \pm SD (range) or $\mathrm{n}(\%)$. COPD: chronic obstructive pulmonary disease; MND: motor neurone disease; RLD: restrictive lung disease. 
TABLE 4 Logistic regression for absolute response

\begin{tabular}{lcc} 
& OR $(95 \% \mathrm{CI})$ & p-value \\
\hline Age & $0.96(0.93-1.00)$ & 0.039 \\
BI-baseline & $1.04(1.03-1.06)$ & 0.000 \\
Performance status & $0.98(0.95-1.02)$ & 0.298 \\
COPD & $0.49(0.07-3.64)$ & 0.486 \\
Cancer & $0.36(0.04-2.94)$ & 0.338 \\
RLD & $0.30(0.03-2.53)$ & 0.266 \\
Sex & $0.75(0.33-1.69)$ & 0.485 \\
Currow & $1.79(0.66-4.87)$ & 0.251 \\
Johnson & $1.20(0.08-19.09)$ & 0.897 \\
Oxberry & $1.50(0.15-14.96)$ & 0.729 \\
\hline
\end{tabular}

Standard error adjusted for 166 clusters in "study". The odds ratio indicates whether the patients with that characteristic were more $(>1)$ or less $(<1)$ likely to respond to morphine, e.g. those with "more" age (older) were less $(<1)$ likely to respond to morphine. BI: breathlessness intensity; COPD: chronic obstructive pulmonary disease; RLD: restrictive lung disease.

secondary analyses from individual studies, we found that worse baseline breathlessness intensity was a strong predictor of response but disease group or functional status was not.

\section{Younger age}

As a relationship with performance status is not apparent from these data, the explanation for the observed improved response rate in younger participants cannot be linked to improved exercise tolerance. Chronic refractory breathlessness seems to be a final common pathway in advanced disease [29], independent of underlying aetiology, and the reduced response in the older person may reflect very long breathlessness trajectories with established central pathways involved in the perception of breathlessness. In addition, central neuronal pathways may become less plastic with age and/or longer duration of breathlessness, and therefore older people have less ability to respond to opioids by modifying their central perception. This study does not include data regarding duration of breathlessness, but this would be interesting.

\section{Baseline intensity of breathlessness}

In contrast to the previous findings that response is unrelated $[16,24]$ or more likely in those with less baseline breathlessness intensity [22], this pooled dataset shows that increased baseline intensity is a highly significant predictor of response. Regression towards the mean would be greater for those with the higher baseline breathlessness intensity, so there would be an expected improvement in those participants, even without intervention [30]. Another way to look at this is that people with a high degree of breathlessness have more scope for improvement than those who begin with only a small amount. The previous two

\section{TABLE 5 Final model from stepwise logistic regression: absolute and relative}

\section{OR $(95 \% \mathrm{Cl}) \quad$ p-value}

Model for "absolute" response
Age
Bl-baseline
Currow
Johnson
Oxberry
Model for "relative" response
Age
Bl-baseline
Currow
Johnson
Oxberry

Standard error adjusted for 166 clusters in "study". The odds ratio indicates whether the patients with that characteristic were more $(>1)$ or less $(<1)$ likely to respond to morphine, e.g. those with "more" age (older) were less $(<1)$ likely to respond to morphine. BI: breathlessness intensity. 
studies were smaller, demonstrating the need to repeat analyses on larger datasets. Furthermore, the participants in the AlLARD et al. [22] study appear to be a different population; much more unwell with a median survival of only 15 days. In contrast, many participants in the ABERNETHY et al. [14], JOHNSON et al. [17] and OXBERRY et al. [16] studies were alive months and even years after study closure. It could be argued that the perception pathway for refractory breathlessness in patients in the ALLARD et al. [22] study had become so established that response to any intervention was less likely. However, this result of ALLARD et al. [22] is most probably a chance finding in a small group.

\section{Disease aetiology}

Excess sympathetic outflow is a recognised pathophysiological response proposed as a possible unifying mechanism for breathlessness and fatigue in CHF; two primary symptoms acting through the complex relationship between skeletal muscle, the ergoreflex and the autonomic nervous system [31]. As skeletal muscle abnormalities and inflammation are also recognised features of advanced cancer and nonmalignant lung disease, it is possible that opioids may have a peripheral, as well as central, effect in the alleviation of breathlessness.

However, we found no association between response and disease aetiology, in keeping with the observation that breathlessness is an end-stage symptom in many diseases [29]. As opioids may alleviate the sensation of breathlessness through central neural pathways [32], this supports the hypothesis that opioids act on a "final common pathway of perception", rather than in any disease-specific manner.

\section{Functional status}

We could not demonstrate a relationship between functional status and opioid response in our pooled dataset, and, although there was a reasonable spread of scores, participants studied were not in the last few weeks of life.

\section{Descriptors}

The subjective experience of breathlessness is complex. The language people use to describe their experience of breathlessness may relate to the mechanism whereby the breathlessness is generated. Initial work in the late 1980s studied the language used by volunteers with breathlessness induced using eight different mechanisms [28]. Further work in people with medical conditions indicates that particular phrases appear to be more common in some diseases causing breathlessness than others. A discussion is beyond the scope of this paper, but a full review was published by GARRARD and WILLIAMS in 2008 [33]. Given the preliminary findings that patients with cardiovascular disease may be more likely to have breathlessness that responds to opioids, we looked at the available descriptor data in this dataset. The only descriptor that showed any evidence of being a predictor was "cannot get enough air". This phrase has been associated with COPD, asthma and CHF. From our data, these breathlessness descriptors do not seem to be a useful addition with regard to prediction of opioid response; however, our sample size for participants with descriptor data is still relatively small $(\mathrm{n}=107)$.

\section{Implications for clinical practice}

One of the "known unknowns" in the pharmacological management of chronic refractory breathlessness relates to the observation that, as with many interventions, not everyone benefits $[13,23,24]$. In people with chronic refractory breathlessness, the number needed to treat has been estimated as 1.6 to gain a $\geqslant 10 \%$ relative improvement at 1 week over the participant's own baseline on a 0-10 NRS scale [24]. The number needed to harm was found to be 4.6, although all adverse reactions reversed when the morphine was discontinued and none resulted in hospital admission. Although there are no reported opioid-related serious adverse events from these studies of appropriately monitored opioids [14, 16, 17, 24], any iatrogenic harm may be significant in vulnerable people with advanced disease [34]. This improved understanding of those whose chronic refractory breathlessness is most likely to improve with opioids would help reduce the numbers exposed to harm without benefit; it is important to identify a priori those who are most likely to respond. Careful titration may minimise adverse effects to nausea and sedation, allowing tolerance to develop, and increasing confidence in patients and prescribers who may be anxious about the use of morphine.

\section{Limitations}

Although this study included the largest pool of patients to date there are still insufficient numbers to draw firm conclusions over some aspects and it should still be considered exploratory. It has been an important opportunity to develop the methodology for pooling data where the measures have been different. We also recognise that a larger dataset for some aspects, such as the relationship between KPS and NYHA status, is 
needed, and we need to continue to add to the database. It also underlines the importance of researchers using common outcome measures to facilitate such individual pooled data analyses.

This analysis only allowed examination of gross measures such as sex, age and disease. More nuanced exploration was not possible, and thought should be given to baseline data collection in future studies that include intensity and other dimensions of breathlessness such as unpleasantness, the descriptor "cannot get enough air" and actual directly measured activity, not simply function.

\section{Conclusions}

These pooled data suggest that a therapeutic trial of morphine for chronic refractory breathlessness is appropriate for patients irrespective of the primary cause of the breathlessness or functional status. Those with worse breathlessness intensity are more likely to gain net benefit; however, this study suggests that this is less likely to be the case for people with milder breathlessness. Opioid therapies should be monitored closely, as the therapeutic index may be narrower for patients such as the elderly with less to gain. Likewise, older people are at particular risk of drug-drug- and drug-host-related adverse events. Therefore, as they may be less likely to benefit, close monitoring is needed to judge whether continued opioid treatment is warranted. Opioids have a role in the management of chronic refractory breathlessness, but the net benefit for individuals must be optimised.

\section{Acknowledgements}

The authors thank Tracey Hawkes (Research Office, Scarborough General Hospital, Scarborough, UK) for able assistance in combining the datasets.

\section{References}

1 Bausewein C, Booth S, Gysels $\mathrm{M}$, et al. Understanding breathlessness: cross-sectional comparison of symptom burden and palliative care needs in chronic obstructive pulmonary disease and cancer. J Palliat Med 2010; 13: $1109-1118$.

2 Currow DC, Plummer JL, Crockett A, et al. A community population survey of prevalence and severity of dyspnea in adults. J Pain Symptom Manage 2009; 38: 533-545.

3 Currow DC, Smith J, Davidson PM, et al. Do the trajectories of dyspnea differ in prevalence and intensity by diagnosis at the end of life? A consecutive cohort study. J Pain Symptom Manage 2010; 39: 680-690.

Abernethy AP, Wheeler JL. Total dyspnoea. Curr Opin Support Palliat Care 2008; 2: 110-113.

5 Booth S, Silvester S, Todd C. Breathlessness in cancer and chronic obstructive pulmonary disease: using a qualitative approach to describe the experience of patients and carers. Palliat Support Care 2003; 1: 337-344.

6 Bausewein C, Booth S, Gysels M, et al. Non-pharmacological interventions for breathlessness in advanced stages of malignant and non-malignant diseases. Cochrane Database Syst Rev 2008; 2: CD005623.

7 Booth S, Bausewein C, Higginson I, et al. Pharmacological treatment of refractory breathlessness. Expert Rev Respir Med 2009; 3: 21-36.

8 Kamal AH, Maguire JM, Wheeler JL, et al. Dyspnea review for the palliative care professional: treatment goals and therapeutic options. J Palliat Med 2012; 15: 106-114.

9 Dorman S, Jolley C, Abernethy A, et al. Researching breathlessness in palliative care: consensus statement of the National Cancer Research Institute Palliative Care Breathlessness Subgroup. Palliat Med 2009; 23: 213-227.

10 Oxberry SG, Bland JM, Clark AL, et al. Minimally clinically important difference (MCID) in chronic breathlessness: every little helps. Am Heart J 2012; 164: 229-235.

11 Ries AL. Minimally clinically important difference for the UCSD Shortness of Breath Questionnaire, Borg Scale, and Visual Analog Scale. COPD 2005; 2: 105-110.

12 Improving research methodology in breathlessness: a meeting convened by the MRC clinical trials unit and the Cicely Saunders Foundation. Palliat Med 2006; 20: 219-220.

13 Johnson MJ, Abernethy AP, Currow DC. Gaps in the evidence base of opioids for refractory breathlessness. A future work plan? J Pain Symptom Manage 2012; 43: 614-224.

14 Abernethy AP, Currow DC, Frith P, et al. Randomised, double blind, placebo controlled crossover trial of sustained release morphine for the management of refractory dyspnoea. BMJ 2003; 327: 523-528.

15 Jennings AL, Davies AN, Higgins JP, et al. A systematic review of the use of opioids in the management of dyspnoea. Thorax 2002; 57: 939-944.

16 Oxberry SG, Torgerson DJ, Bland JM, et al. Short-term opioids for breathlessness in stable chronic heart failure: a randomized controlled trial. Eur J Heart Fail 2011; 13: 1006-1012.

17 Johnson MJ, McDonagh TA, Harkness A, et al. Morphine for the relief of breathlessness in patients with chronic heart failure - a pilot study. Eur J Heart Fail 2002; 4: 753-756.

18 Chua TP, Harrington D, Ponikowski P, et al. Effects of dihydrocodeine on chemosensitivity and exercise tolerance in patients with chronic heart failure. J Am Coll Cardiol 1997; 29: 147-152.

19 Jensen D, Alsuhail A, Viola R, et al. Inhaled fentanyl citrate improves exercise endurance during high-intensity constant work-rate cycle exercise in chronic obstructive pulmonary disease. J Pain Symptom Manage 2012; 43: 706-719.

20 Natalini G, Di Maio A, Rosano A, et al. Remifentanil improves breathing pattern and reduces inspiratory workload in tachypneic patients. Respir Care 2011; 56: 827-833.

21 Mahler DA, Murray JA, Waterman LA, et al. Endogenous opioids modify dyspnoea during treadmill exercise in patients with COPD. Eur Respir J 2009; 33: 771-777. 
22 Allard P, Lamontagne C, Bernard P, et al. How effective are supplementary doses of opioids for dyspnea in terminally ill cancer patients? A randomized continuous sequential clinical trial. J Pain Symptom Manage 1999; 17: 256-265.

23 Currow DC, Plummer J, Frith P, et al. Can we predict which patients with refractory dyspnea will respond to opioids? J Palliat Med 2007; 10: 1031-1036.

24 Currow DC, McDonald C, Oaten S, et al. Once-daily opioids for chronic dyspnea: a dose increment and pharmacovigilance study. J Pain Symptom Manage 2011; 42: 388-399.

25 Powers J, Bennett SJ. Measurement of dyspnea in patients treated with mechanical ventilation. Am J Crit Care 1999; 8: 254-261.

26 Ma C, Bandukwala S, Burman D, et al. Interconversion of three measures of performance status: an empirical analysis. Eur J Cancer 2010; 46: 3175-3183.

27 Johnson MJ, Bland JM, Davidson PM, et al. The relationship between two performance scales: New York Heart Association Class and Karnofsky Performance Scale. J Pain Symptom Manage 2013 [In press DOI: 10.1016/j. jpainsymman.2013.05.006].

28 Simon PM, Schwartzstein RM, Weiss JW, et al. Distinguishable sensations of breathlessness induced in normal volunteers. Am Rev Respir Dis 1989; 140: 1021-1027.

29 Solano JP, Gomes B, Higginson IJ. A comparison of symptom prevalence in far advanced cancer, AIDS, heart disease, chronic obstructive pulmonary disease and renal disease. J Pain Symptom Manage 2006; 31: 58-69.

30 Bland JM, Altman DG. Some examples of regression towards the mean. BMJ 1994; 309: 780.

31 Piepoli M, Clark AL, Volterrani M, et al. Contribution of muscle afferents to the hemodynamic, autonomic, and ventilatory responses to exercise in patients with chronic heart failure: effects of physical training. Circulation 1996; 93: 940-952.

32 von Leupoldt A, Sommer T, Kegat S, et al. Dyspnea and pain share emotion-related brain network. Neuroimage 2009; 48: 200-206.

33 Garrard AK, Williams M. The language of dyspnoea: a systematic review. The Internet Journal of Allied Health Sciences and Practice, 2008. http://ijahsp.nova.edu/articles/vol6num1/garrard.htm Date last accessed: August 4, 2012.

34 Currow DC. Why don't we do more rigorous clinical research so that we can stop experimenting on patients? J Palliat Med 2010; 13: 636-637. 